\title{
LA EDUCACIÓN EMOCIONAL Y LA COMUNICACIÓN ESCOLAR
}

\section{EMOTIONAL EDUCATION AND COMMUNICATION SCHOOL}

\begin{abstract}
AUTOR
Arís Redó, Nuria: Universidad Internacional de Cataluña. Barcelona (España). Vicedecana de la Facultad de Educación.

nuria@cir.uic.es

\section{RESUMEN}

Como seres sociales nos resulta vital el autoconocimiento y ser capaces de expresar nuestros sentimientos, nuestras emociones generando la mejor "versión" de uno mismo. Las interacciones entre personas, por otra parte, no se desarrollan en un vacío de sentimientos y la dimensión emocional es determinante en el modelo de comunicación personal.

La emoción constituye un elemento esencial de la comunicación y por ello debemos considerar sus potenciales educativos en el trato con los niños y niñas pequeños.

Ciertamente, el profesor es siempre un modelo para el alumno por lo que es fundamental que esté en disposición de unas dimensiones personales idóneas, y mas específicamente, que haya potenciado su competencia socio-emocional y comunicativa.
\end{abstract}

\section{PALABRAS CLAVE}

Comunicación - Emocional - Escolar - Educación - Profesores

\begin{abstract}
As social beings the self-knowledge is vital and be able to express our feelings, our emotions generating better "version" of oneself. Interactions between people, on the other hand, do not develop in a vacuum of feelings and the emotional dimension is determinant in personal communication model. The emotion is an essential element of communication and therefore we must consider their educational potential in the education of small boys and girls. Certainly the teacher is always an example by what is fundamental to have provision of suitable personal dimensions, and more specifically, to strengthened its socio-emotional and communicative competence.
\end{abstract}




\section{KEY WORDS}

Communication - Emotional -Scholar- Education- Teachers

\section{ÍNDICE}

\section{COMUNICACIÓN Y GESTIÓN EMOCIONAL}

- 1.1 Base teórica de la Gestión Emocional

- 1.2 Relaciones con el modelo de comunicación

2. IMPLICACIONES EDUCATIVAS

3. CONCLUSIONES

4. BIBLIOGRAFIA

\section{COMUNICACIÓN Y GESTIÓN EMOCIONAL}

Pensar en la mejor forma de comunicar algo, sobre todo cuando se quiere transmitir con eficacia, es pensar en un medio capaz de expresar con fidelidad toda esa carga de subjetividad que nos define como seres humanos.

El tema de las relaciones entre las emociones, la razón y la comunicación no es nuevo, pero actualmente hay una atención emergente por parte de científicos, filósofos, psicólogos y educadores. Para dar una base a las relaciones entre emoción, razón y comunicación es preciso considerar las aportaciones científicas.

\subsection{Base o teórica de la Gestión Emocional}

El neurobiólogo Damasio (2001), cuyos estudios sobre el cerebro confirman que el sistema límbico y la corteza se influyen entre sí, explica cómo la emoción influye sobre la cognición, y especialmente sobre la memoria. Recordamos determinados episodios vivenciales pero olvidamos otros.

Al hablar de la memoria es preciso destacar que no solo se relaciona con el hecho de retener cierta información sino que la memoria forma parte de casi todos los procesos cognitivos: la percepción, toma de decisiones, aprendizaje, planificación, establecimiento de prioridades, creatividad, etc. Por ello tiene un amplio impacto la influencia de la emoción en la cognición.

En esa misma línea LeDoux (1999) ha demostrado que es posible estudiar la emoción del modo en que se ha estudiado la razón; es decir analizando cómo el cerebro procesa estímulos. Cuando se trata de estímulos emocionales se produce una respuesta emocional. Sus investigaciones le han llevado al convencimiento que la emoción llega a 
controlar el pensamiento. Lo argumenta considerando que la emoción es más fuerte que la razón. Es decir, es posible que la razón llegue a controlar la reflexión, y en cambio es muy difícil que el pensamiento racional controle la emoción. Por ello, ante casos de ansiedad o depresión, la razón puede reflexionar sobre lo que esta pasando y puede desear decir basta, pero casi nunca lo consigue, puesto que eliminar el estrés o la ansiedad pasa necesariamente por la gestión emocional.

Por su parte, Maturana (2001) desde el punto de vista biológico ha definido a las emociones como las "disposiciones corporales dinámicas que definen los distintos dominios de acción en que nos movemos".

De ahí que cuando uno cambia de emoción cambia de dominio de acción. Es decir si cambian nuestras circunstancias emocionales cambia nuestra forma de razonar.

Por ello considera que nuestra racionalidad se fundamenta en la realización de operaciones condicionadas por la dimensión emocional. En cierta manera se considera que la conciencia y el pensamiento se originan desde la disposición emocional que filtra la realidad.

Podemos afirmar entonces que cada emoción predispone a cierta gama de acciones e imposibilita a otras. Por tanto "todas las decisiones en el hombre son emocionales porque al final de cuentas todo empieza con una emoción, y en última instancia, es una emoción la que inclina la balanza hacia un lado u otro. Si sólo contáramos con la razón, no decidiríamos nunca nada, dada la complejidad casi infinita que supone evaluar correctamente la selva de datos disponibles" (Punset 2005).

De hecho, la importancia que desempeñan las emociones en los procesos intelectuales está actualmente tan admitida, que hoy en día se está buscando convertir a los ordenadores actuales en ordenadores emocionales para que sean auténticas máquinas inteligentes (Picard, 1997) ${ }^{1}$.

\subsection{Relaciones con el modelo de comunicación}

Una vez establecido que razón y emoción interactúan juntas, la siguiente reflexión que nos surge es que sobre la comunicación. Cuando nos referimos a la comunicación humana tenemos que asumir que no puede existir una comunicación que sea visceral (emocional) por un lado, y cerebral (racional) por otro. En mayor o menor grado, la comunicación tiene inevitablemente ambas dimensiones. No tenemos un sistema para tratar lo intelectual y otro para lo emocional, sólo tenemos un sistema nervioso y un sistema psicológico.

\footnotetext{
1 Rosalind Picard, profesora del famoso Media Laboratory del Massachussets Institute ofTechnology, ha sido una de las pioneras en este campo. El ambicioso proyecto de Picard contempla en entre otra cuestiones, el diseño de ordenadores que reconozcan las emociones humanas.
} 
Como señala Maturana (1993) "fluimos en nuestro emocionar a través del fluir de nuestras conversaciones". Esto quiere decir que en el lenguaje se manifiestan nuestras emociones y sentimientos más diversos ${ }^{2}$.

Al hablar, los argumentos y la razones y justificaciones sobre el intercambio de información se van construyendo sobre una base emocional que predispone hacia una determinada acción (Maturana, 2000).

Habitualmente nuestra dimensión social esta repleta de oralidad y de interacción verbal. A través de las palabras damos sentido al momento de la distensión, de la presión cotidiana en la risa, en el humor, pero también al momento de la desesperación, de la agresión, del conflicto, de la mentira, de la ofensa, del malentendido y de la incomprensión. Es a partir de esta realidad que se establece el carácter generativo del lenguaje, en tanto que puede describir la realidad, pero especialmente porque puede crear realidades. Es decir, el lenguaje habla sobre las cosas y hace que sucedan cosas. Al construir nuevas realidades en cierta manera, podemos considerar que lo son a partir del lenguaje que dan razón de ellas (Gergen, 1996). El lenguaje pues incide en la realidad, o sea el hablar tiene consecuencias. Así podemos decir que desde niños aprendemos "lenguaje y gestión de emociones" en nuestra vida cotidiana. Vamos moldeando, mediante el lenguaje, nuestras emociones y estados de ánimo en el transcurso de nuestras conversaciones. Por eso cada cosa que nos decimos tiene consecuencias e incluso cuando verbalizamos acerca de nosotros mismos, se detectan las dimensiones emocionales.

Ahora bien, antropológicamente sabemos que esta capacidad de acción comunicativa en el hombre, cuyo eje central son las conversaciones, no es más que la inteligencia social, relacional o paradigmática.

Según Bruner (1998) dicha inteligencia tiene una habilidad básica que consiste globalmente en la capacidad de construir creencias sobre las creencias que otros tienen o atribuírselas a algo o a alguien distinguiéndolas de las propias. Por tanto, podemos afirmar que la dotación más característica de nuestra especie es ser capaces de hacer una lectura y constante interpretación de la mente y del contenido de la mente de los demás.

2 Recordemos que el lenguaje es una adquisición precaria, ya que la carga afectiva muy propia de la comunicación subjetiva-animal (lenguaje corporal), es la que habría originado la aparición del lenguaje (signos) como tal. Por eso, al principio, el lenguaje no expresa pensamientos o ideas, sino sentimientos y afectos, y siendo éste su punto de origen, la comunicación corporal se hace un lenguaje mucho más compartido que la lengua hablada, pues es una comunicación compartida por la especie. De ella se deriva el lenguaje conceptual o inteligible, que a diferencia del emotivo podrá trascender el aquí y el ahora, con lo cual llegamos a ser contemporáneos de algo más que el instante. 
En esta capacidad se fundamenta todo el proceso de socialización (comunicación y cooperación) que a su vez condiciona en gran medida el resto de la actividad cognitiva. Esto es así porque tanto el lenguaje y las emociones (además del comportamiento corporal) son nuestros constituyentes primarios, aquellos tipos de comportamientos que originan y posibilitan nuestras relaciones interpersonales y que nos hacen, como seres humanos, actuar como actuamos.

El enfoque sistémico, Bronfenbrenner (1986), permite establecer las bases, el punto de partida para caracterizar al ser humano como sistema abierto que se relaciona con otros sistemas abiertos (otras personas) y que forma parte de sistemas abiertos ${ }^{3}$ (como la familia, el grupo de amigos, la pareja, la escuela...).

En cuanto al lenguaje escrito, a diferencia del oral es descontextualizado porque surge de una representación en el pensamiento, de una situación comunicativa determinada que no está presente. Así pues, nosotros mismos nos vemos obligados a crear la situación, mejor dicho, a representárnosla en el pensamiento. En cierto sentido, la utilización del lenguaje escrito presupone una actitud que exige una mayor independencia, una mayor voluntariedad y una mayor libertad con respecto a ella (Vigotsky, 1995) ${ }^{4}$. Entonces, si la escritura es más compleja que la oralidad es porque implica una actitud y una actividad consciente, reflexiva y deliberada. Al no existir en la escritura la presencia física del otro, del lector de modo simultáneo, el escritor debe tenerlo en mente al momento de hacer su texto.

\section{IMPLICACIONES EDUCATIVAS}

En base a todo lo considerado anteriormente que nuestra "propuesta de comunicación" es en gran manera mediadora e incluso determinante en nuestra "propuesta de relación". Por ello planteamos la necesidad de profundizar en el conocimiento del estilo de comunicación que adopta cada persona.

De manera subyacente todos los seres humanos tenemos en nuestro interior diversos modelos o estilos comunicativos. Son las circunstancias y la evaluación emocional de las

3 Para Bronfenbrenner, desde el enfoque sistémico cualquier organismo, grupo humano, institución... puede caracterizarse como sistema abierto donde el modelo de comunicación es fundamental.

4 Vigotsky los clasifica en herramientas y en signos. Los primeros constituyen instrumentos concretos que facilitan las relaciones con la naturaleza en el aspecto externo, por ejemplo, el lápiz, el bolígrafo o el ordenador para el caso de la escritura. Los signos, por su parte, constituyen instrumentos que funcionan a nivel psicológico y se orientan hacia el mundo interiorizado. Por ejemplo, cuando escribimos un e-mail, el ordenador funciona como un mediador de tipo herramienta, y el sistema escrito constituye un mediador signo, pues permite la acción del discurso narrativo en forma gráfica 
mismas lo que permite emerger más claramente uno de ellos por encima de los demás. Así pues, podemos considerar que todos tenemos rasgos de tres estilos comunicativos. En función de las experiencias procesadas por cada persona se tiende a tener predisposición por "responder" desde uno de estos modelos.

Dichos modelos comunicativos, los podemos explicar agrandes rasgos, como el "modelo dominante", el "modelo sumiso" y por ultimo "el cooperador". Cabe decir que ninguno de dichos modelos opera de una manera "clara o nítida", siendo una combinación de rasgos y características de cada uno de ellos los que emergen según los requerimientos de interacción comunicativa en concreto.

Si lo que se busca es conseguir la mejor manera de relacionarse con lo demás es fácil deducir que el "modelo cooperador" debería ser el patrón que aflorara la mayoría de las veces. Ello nos daría la posibilidad de generar la mejor versión de uno mismo. Da sentido a la postura capaz de armonizar las propias emociones y razones con las del otro, entendiendo que las de los demás son tan relevantes como las propias.

Es decir, estamos hablando de una comunicación en términos de igualdad pero desde la aceptación de la subjetividad diferencial de cada cual.

Pero este modelo "coperador" es el enfoque menos usual y ciertamente es fácil describirlo pero cuesta mucho vivenciarlo. Resulta difícil, dada la complejidad de nuestras relaciones con los demás, poder satisfacer los propios deseos y además estar dispuesto a que se satisfagan también en alto grado los de la otra parte.

Es preciso considerar que en cierta manera, nos resulta especialmente difícil por la sencilla razón de que no nos hemos "preparado" para ello. Desde la más tierna infancia constantemente nos llegan "inputs" comunicativos de carácter competitivito que no dan margen para la cooperación. Por otro lado, el dinamismo del momento comunicativo nos impulsa a aplicar respuestas inmediatas basadas en conductas automatizadas (a veces muy poco racionales y de efectos devastadores).

Por ello queremos considerar los potenciales educativos de la comunicación como dimensión trasversal en formación integral de la persona. Si la comunicación es un aprendizaje vivencial, que se forja en las experiencias y en las relaciones emocionales "inter y intra" subjetivas del día a día de la persona, debería considerarse el gran potencial desde las dimensiones educativas.

Conocer y experimentar el modelo "coopertaivo" desde las primeras palabras, desde la socialización más primaria, facilitaría que cada persona estuviera en la mejor disposición para generar su mejor versión de "ser humano". Por ello, insistimos en que las implicaciones en el ámbito educativo y escolar son fundamentales. 
Los niños de educación infantil y primaria, nuestros escolares de hoy son los ciudadanos de mañana, crecerán y desarrollarán sus potencialidades desde una determinada realidad, y desde una interacción llena de significaciones.

De hecho los niños, ya desde muy pequeños, entienden que los demás son seres con sentimientos, creencias y pensamientos propios sobre las cosas y los acontecimientos. Si el maestro es un ejemplo de comunicación inteligente y cooperativa tendrá la posibilidad de proyectarlo en su aula, y los alumnos lo asimilaran por modelaje significativo. Pero si no hay intencionalidad educativa para que la comunicación no sea desde un planteamiento comunicativo de estilo cooperativo (delfín), muy a menudo se tiende a repetir los modelos más habituales de nuestra sociedad, el agresivo o el sumiso (carpa o tiburón).

Ciertamente, el profesor es siempre un modelo para el alumno por lo que es fundamental que esté en disposición de unas dimensiones personales idóneas, y más específicamente, que haya potenciado su competencia socio-emocional.

Tener un buen logro en dicha competencia permitirá el ser flexibles, tolerantes, con sentido del humor, capacidad para resolver los conflictos de manera constructiva y dialogante, capacidad de relajarse, y potencial de innovación y creatividad ante los retos cotidianos.

En la complejidad de nuestro presente y aun más en el futuro, el maestro/a deberá estar en disposición de observar, diagnosticar y elaborar estrategias de intervenciones específicas y adaptadas a las situaciones concretas del aula, del conjunto global de estudiantes, y singular de cada persona, y en definitiva a los retos de la sociedad que se trasladan al quehacer cotidiano de su clase.

No es un reto fácil, pero si es posible. Entendemos que se debe abordar desde una visión global y trasversal de las funciones de la escuela con un compromiso claro con la educación emocional

\section{CONCLUSIONES}

- Las claves de una comunicación inteligente que armonice emoción y razón pasan por la autoconocimiento emocional, y la gestión de la comunicación y de las relaciones.

- Nos referimos autoconocimiento emocional como la capacidad de explorar y evaluar los propios pensamientos y creencias así como de reconocer las propias reacciones. 
- Ello implica buscar explicaciones alternativas y la reflexión sobre las propias reacciones.

- Es preciso reflexionar sobre los potenciales educativos de la comunicación como dimensión trasversal en formación integral de la persona.

- El profesor, el maestro es siempre un modelo para el alumno por lo que es fundamental que esté en disposición de unas dimensiones personales idóneas

- Tener un buen logro en dichos aspectos permitirá al futuro maestro/a ampliar su potencial de innovación y creatividad ante los retos cotidianos.

\section{BIBLIOGRAFÍA}

- AUSTIN, J. (1995) Cómo hacer cosas con palabras. Barcelona. Paidós.

- BRONFENBRENNER, U. (1986) Ecología del desarrollo humano. Barcelona. Paidós

- $\quad$ BRUNER J. (1998) Realidad mental y mundos posibles. Barcelona. Gedisa.

- FERNANDEZ BERROCAL P; RAMOS DIAZ, N. (2004) Desarrolla tu inteligencia emocional. Barcelona. Kairós.

- GADNER, H. (2001) La inteligencia reformulada. Las inteligencias múltiples en el siglo XXI. Barcelona. Paidós.

- GERGEN, K. (1996) Realidades y Relaciones. Madrid. Paidós

- GOLEMAN, D. (1997) Inteligencia Emocional. Barcelona. Círculo de Lectores.

- LEDOUX, J. (1999) El cerebro emocional. Barcelona. Planeta 
- MARINA, J. (1996) El laberinto sentimental: Barcelona. Anagrama.

- MAturanA, H. (1993) Amor y Juego, Fundamentos Olvidados de lo Humano. Santiago de Chile. Instituto de Terapia Cognitiva.

- PICARD, R. (1997) Ordenadores Emocionales. Barcelona. Ariel S.A.

- VIGOTSKY, L. (1995) Pensamiento y Lenguaje. Nueva edición a cargo de Alex Kozulin. Barcelona. Paidós Ibérica S.A. 